
duas épocas de colheita. Horticultura Brasileira 29: 456-460.

\title{
Adubação fosfatada em inhame em duas épocas de colheita
}

\author{
Arnaldo Nonato P de Oliveira; Francisco A Oliveira; Leossávio C de Sousa; Ademar P de Oliveira; Jandiê \\ A da Silva; Damiana F da Silva; Natália V da Silva; Rodolfo R Santos \\ UFPB-CCA, C. postal 02, 58397-000 Areia-PB; ademar@pp.cnpq.br
}

\section{RESUMO}

O baixo teor de fósforo nos solos tropicais torna essencial pesquisas sobre sua adubação em culturas pouco estudadas como o inhame. Assim, o objetivo foi avaliar a produtividade do inhame (cultivar Da Costa) em função de doses de fósforo e épocas de colheita. De fevereiro a dezembro de 2009 foi conduzido um experimento em delineamento experimental de blocos casualizados, em parcelas subdivididas, em quatro repetições. Nas parcelas foram avaliadas seis doses de fósforo $\left(0,100,200,300,400\right.$ e $\left.500 \mathrm{~kg} \mathrm{ha}^{-1} \mathrm{de}_{2} \mathrm{O}_{5}\right)$, e nas subparcelas duas épocas de colheitas (sete e nove meses após o plantio). Os pesos máximos de túberas colhidas aos sete e aos nove meses foram 1,94 e 2,20 kg com 245 e $240 \mathrm{~kg} \mathrm{ha}^{-1}$ de $\mathrm{P}_{2} \mathrm{O}_{5}$, respectivamente. Não houve efeito das doses de fósforo na produtividade total aos sete meses, sendo o valor médio $13 \mathrm{t} \mathrm{ha}^{-1}$. A máxima produtividade

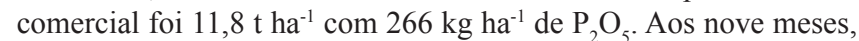
as máximas produtividades total $\left(24,7 \mathrm{tha}^{-1}\right) \mathrm{e}$ comercial $\left(20,5 \mathrm{tha}^{-1}\right)$ foram obtidas com 285 e $226 \mathrm{~kg} \mathrm{ha}^{-1}$ de $\mathrm{P}_{2} \mathrm{O}_{5}$, respectivamente. As máximas percentagens de túberas classificadas como primeira foram 80 e $90 \%$ aos sete meses e noves meses com 320 e $277 \mathrm{~kg} \mathrm{ha}^{-1} \mathrm{de}$ $\mathrm{P}_{2} \mathrm{O}_{5}$, respectivamente. As doses econômicas foram de 219 e $233 \mathrm{~kg}$ $\mathrm{ha}^{-1}$ de $\mathrm{P}_{2} \mathrm{O}_{5}$ para obtenção de $20,19 \mathrm{t} \mathrm{ha}^{-1}$ e $12,88 \mathrm{t} \mathrm{ha}^{-1}$ de túberas comerciais aos nove e sete meses, representando incrementos de 19,17 e 3,9 t ha ${ }^{-1}$ em relação à ausência do insumo, respectivamente

Palavras-chave: Dioscorea cayennensis, adubação fosfatada, produção e qualidade de túberas.

\begin{abstract}
Phosphate fertilization in yam in two harvest seasons

The low content of phosphorus in tropical soils makes essential the research about fertilization in crops which are poorly studied such as yam. Thus, this study aimed to evaluate the yam productivity (cultivar Da Costa) depending on phosphorus doses and harvest seasons. From February to December 2009, an experiment was carried out using the randomized blocks experimental design in subdivided plots, with four replications. In the plots six doses of phosphorus were evaluated $\left(0,100,200,300,400\right.$ and $500 \mathrm{~kg} \mathrm{ha}^{-1}$ of $\left.\mathrm{P}_{2} \mathrm{O}_{5}\right)$, and in the subplots two harvest seasons (seven and nine months after planting). The highest weight of tubers in seven and nine months was 1.94 and $2.20 \mathrm{~kg}$ with 245 and $240 \mathrm{~kg} \mathrm{ha}^{-1}$ of $\mathrm{P}_{2} \mathrm{O}_{5}$, respectively. There was no significant effect of phosphorus doses on the total productivity in seven months and the average value was $13 \mathrm{tha}^{-1}$. The highest marketable productivity was $11.8 \mathrm{t} \mathrm{ha}^{-1}$ with $266 \mathrm{~kg} \mathrm{ha}^{-1}$ of $\mathrm{P}_{2} \mathrm{O}_{5}$. In nine months, the highest total and marketable yield $(24.7$ and $20.5 \mathrm{t}$ $\mathrm{ha}^{-1}$, respectively) was achieved with the application of 285 and 226 $\mathrm{kg} \mathrm{ha}^{-1}$ of $\mathrm{P}_{2} \mathrm{O}_{5}$, respectively. The yield of tubers classified as first was 80 and $90 \%$ in seven and nine months, respectively, and was obtained with the application of 320 and $277 \mathrm{~kg} \mathrm{ha}^{-1}$ of $\mathrm{P}_{2} \mathrm{O}_{5}$, respectively. The economic doses were 219 and $233 \mathrm{~kg} \mathrm{ha}^{-1}$ of $\mathrm{P}_{2} \mathrm{O}_{5}$ to obtain $20.19 \mathrm{t}$ $\mathrm{ha}^{-1}$ and $12.88 \mathrm{tha}^{-1}$ of marketable tubers in seven and nine months, representing increments of 19.17 and $3.9 \mathrm{t} \mathrm{ha}^{-1}$ in comparison to no application of phosphorus, respectively.
\end{abstract}

Keywords: Dioscorea cayennensis, phosphate fertilization, quality and production of tubers.

(Recebido para publicação em 17 de agosto de 2010; aceito em 30 de setembro de 2011) (Received on August 17, 2010; accepted on September 30, 2011)

$\mathrm{O}$ inhame é uma hortaliça que produz túberas ricas em compostos energéticos, vitaminas do complexo $\mathrm{B}$ e alto teor de amido, assumindo importante papel na cadeia alimentar e no desenvolvimento da agricultura familiar no Brasil (Oliveira et al., 2007). No estado da Paraíba, notadamente na mesorregião da Mata Paraibana, o cultivo do inhame vem sendo praticado para atender a crescente demanda do mercado interno e externo. Entretanto, mesmo em condições climáticas ideais para o cultivo, seu rendimento médio ainda continua baixo, o que pode ser atribuído à baixa fertilidade natural dos solos nas áreas de cultivo (Santos et al., 2007).

A grande maioria dos solos brasileiros é de reação ácida, de baixa fertilidade e elevada capacidade de retenção de fósforo, o que leva à necessidade de aplicação de doses elevadas desse nu- triente, contribuindo para o aumento nos custos de produção (Moura et al., 2001).

No cultivo de hortaliças, o emprego do fósforo favorece o desenvolvimento do sistema radicular, aumentando a absorção de água e de nutrientes, refletindo em aumento no rendimento dos produtos colhidos (Avalhaes et al., 2009). Pesquisas revelaram resposta das hortaliças à adubação fosfatada, com aumento de produção (Silva et al., 2001; Lana et al., 
2004; Oliveira et al., 2006).

$\mathrm{O}$ inhame requer um nível alto de nutrientes. Durante as seis primeiras semanas de crescimento, a planta se utiliza das reservas nutritivas contidas na túbera-semente. A partir deste período, os nutrientes desempenham papel importante em cada fase do seu desenvolvimento. A presença do fósforo é importante durante a primeira metade do ciclo de vida do inhame (Santos, 1998), cuja finalidade é dar suporte ao crescimento vegetativo, mas altas produções serão obtidas quando o mesmo estiver disponível e em quantidades adequadas. Estudos sobre os efeitos do fósforo na nutrição e produção do inhame são poucos, o que é motivo de preocupação para o manejo adequado da sua adubação. Souto (1989) detectou resposta positiva na produção de túberas com a aplicação de fertilizantes nitrogenados e fosfatados e, Oliveira (2002) relata que a aplicação de fertilizantes nessa cultura, principalmente fósforo, torna-se importante durante o crescimento das plantas, em virtude do fato de que altas produções são obtidas quando o mesmo está disponível para as mesmas, em todos os estágios de crescimento, e em quantidades adequadas.

A colheita do inhame pode ser realizada aos sete meses, caracterizada pela "capação", ou aos nove meses. A primeira colheita é realizada para comercialização de túberas no período de entressafra e proporcionar a produção futura de túberas-semente, uma vez que as plantas capadas permanecem no campo, por mais dois meses. A segunda colheita, caso não tenha sido efetuada a prática da "capação", é realizada com o objetivo de se obter a produção de túberas maduras.

Normalmente, a colheita precoce (sete meses após o plantio) resulta em menor produtividade e peso médio de túberas (Oliveira et al., 2001) e a adubação com fósforo poderia melhorar o rendimento do inhame nas épocas da colheita devido à sua influência na produção de raízes. Dessa forma objetivou-se avaliar o comportamento do inhame com o emprego de doses de fósforo em duas épocas de colheita.

\section{MATERIAL E MÉTODOS}

O trabalho foi desenvolvido em área experimental da Universidade Federal da Paraíba, em Areia, de fevereiro a novembro de 2009 em um Neossolo Regolítico Psamítico Típico (Embrapa, 1999), textura areia franco, com as seguintes características químicas e físicas: $\mathrm{pH}$ em $\mathrm{H}_{2} \mathrm{O}=5,9 ; \mathrm{P}($ Mehlich $)=$ $10,41 \mathrm{mg} \mathrm{dm}^{-3} ; \mathrm{K}=34,12 \mathrm{mg} \mathrm{dm}^{-3} ; \mathrm{Al}$ trocável $=0,65 \mathrm{cmol}_{c} \mathrm{dm}^{-3} ; \mathrm{Ca}+\mathrm{Mg}=$ $3,35 \mathrm{cmol}_{\mathrm{c}} \mathrm{dm}^{-3}$ e $12,52 \mathrm{~g} \mathrm{~kg}^{-1}$ de matéria orgânica (Embrapa, 1997a); areia= $841,50 \mathrm{~g} \mathrm{~kg}^{-1}$; silte $=88,00 \mathrm{~g} \mathrm{~kg}^{-1}$; argila $=$ $70,50 \mathrm{~g} \mathrm{~kg}^{-1}$; densidade global=1,37 $\mathrm{g}$ $\mathrm{cm}^{-3}$; densidade de partículas $=2,61 \mathrm{~g}$ $\mathrm{dm}^{-3}$; e porosidade total $=0,47 \mathrm{~m}^{3} \mathrm{~m}^{-3}$. O preparo do solo constou de aração, gradagem, confecção de leirões e abertura de covas de plantio.

O delineamento experimental foi de blocos casualizados, em parcelas subdivididas, em quatro repetições. Nas parcelas foram avaliadas seis doses de $\mathrm{P}_{2} \mathrm{O}_{5}(0,100,200,300,400$ e $500 \mathrm{~kg}$ $\left.\mathrm{ha}^{-1}\right)$, e nas subparcelas duas épocas de colheitas (sete e nove meses). As parcelas e subparcelas foram constituídas de 20 plantas cada, espaçadas em 1,2 x 0,6 $\mathrm{m}$, todas consideradas uteis.

Além do fornecimento das doses de $\mathrm{P}_{2} \mathrm{O}_{5}$ avaliadas nessa pesquisa, por recomendação do laboratório de Química e Fertilidade da UFPB (Embrapa, 2007b) foram adicionados $15 \mathrm{t} \mathrm{ha}^{-1} \mathrm{de}$ esterco bovino e $70 \mathrm{~kg} \mathrm{ha}^{-1}$ de $\mathrm{K}_{2} \mathrm{O}$. Na adubação de cobertura foi fornecido 80 $\mathrm{kg} \mathrm{ha}^{-1}$ de $\mathrm{N}$, parcelado em partes iguais aos 60 e 90 dias após o plantio. Como fonte de $\mathrm{P}_{2} \mathrm{O}_{5}$ N e $\mathrm{K}_{2} \mathrm{O}$ foram usados o superfostato simples, sulfato de amônio e cloreto de potássio, respectivamente.

No plantio, foram utilizadas 20 porções de túberas-semente por parcela com peso médio de aproximadamente $200 \mathrm{~g}$, da cultivar Da Costa e enterrados a $10 \mathrm{~cm}$ de profundidade do topo do leirão. Durante a condução do experimento foram executadas capinas manuais com o auxílio de enxadas, amontoa, irrigação pelo sistema de aspersão convencional e tutoramento tradicional, com um tutor (vara de bambu).

Foram realizadas colheitas aos sete meses do plantio época em que as túberas encontram-se imaturas e aos nove meses após o plantio, quando as túberas atingiram sua completa maturação fisiológica, caracterizado pela presença de ramos e folhas senescentes. Nas duas colheitas, foram avaliados peso médio de túberas comerciais, produtividade total e comercial de túberas e percentagem de túberas classificadas como primeira. Foram consideradas túberas comerciais aquelas com peso variando de 1,5 a 2,0 $\mathrm{kg}$, e as classificadas como primeira, as túberas comerciais com característica para exportação (sem deformação e ausência de sintomas de ataques de nematóides), conforme Santos (1996).

Os resultados foram submetidos à análises de variância e de regressão polinomial, utilizando-se o teste $\mathrm{F}$ para comparação dos quadrados médios, empregando-se o "software" SAEG (2000). $\mathrm{Na}$ análise de regressão utilizaram-se os modelos linear e quadrático, sendo selecionado aquele capaz de melhor expressar cada característica. A dose de máxima eficiência econômica de $\mathrm{P}_{2} \mathrm{O}_{5}$ foi calculada igualando-se a derivada primeira da equação de regressão à relação entre preços do insumo ( $\mathrm{R} \$ / \mathrm{kg}$ de $\left.\mathrm{P}_{2} \mathrm{O}_{5}\right)$ e do produto ( $\mathrm{R} \$ / \mathrm{kg}$ de túberas) (Raij, 1991; Natale et al., 1996). Os preços vigentes em Areia-PB em dezembro de 2008, foram $\mathrm{R} \$ 2,60 / \mathrm{kg}$ de $\mathrm{P}_{2} \mathrm{O}_{5}$ e $\mathrm{R} \$$ $1,00 / \mathrm{kg}$ de túberas. O preço do insumo foi aquele praticado no comércio local, e o preço do inhame foi o valor pago pelos atacadistas

\section{RESULTADOS E DISCUSSÃO}

Houve efeito significativo das doses de $\mathrm{P}_{2} \mathrm{O}_{5}$ e das épocas de colheita sobre $\mathrm{o}$ peso médio de túberas comerciais, produtividade total e comercial de túberas e sobre a percentagem de túberas classificadas como primeira (Figuras 1 e 2).

Os pesos médios máximos de túberas aos sete e aos nove meses foram 1,94 e $2,20 \mathrm{~kg}$, obtidos nas doses de 245 e $240 \mathrm{~kg} \mathrm{ha}^{-1}$ de $\mathrm{P}_{2} \mathrm{O}_{5}$ (Figura 1A), respectivamente. $O$ peso médio de túberas foi semelhante nas duas épocas de colheita, ao contrário de Freitas Neto (1999) e Barbosa (2004), que verificaram incrementos de 31 e $18 \%$ no peso médio de túberas colhidas aos nove meses em relação à colheita aos sete meses, respectivamente. Para a colheita efetuada aos sete meses, não houve efeito das doses de fósforo na produtividade 

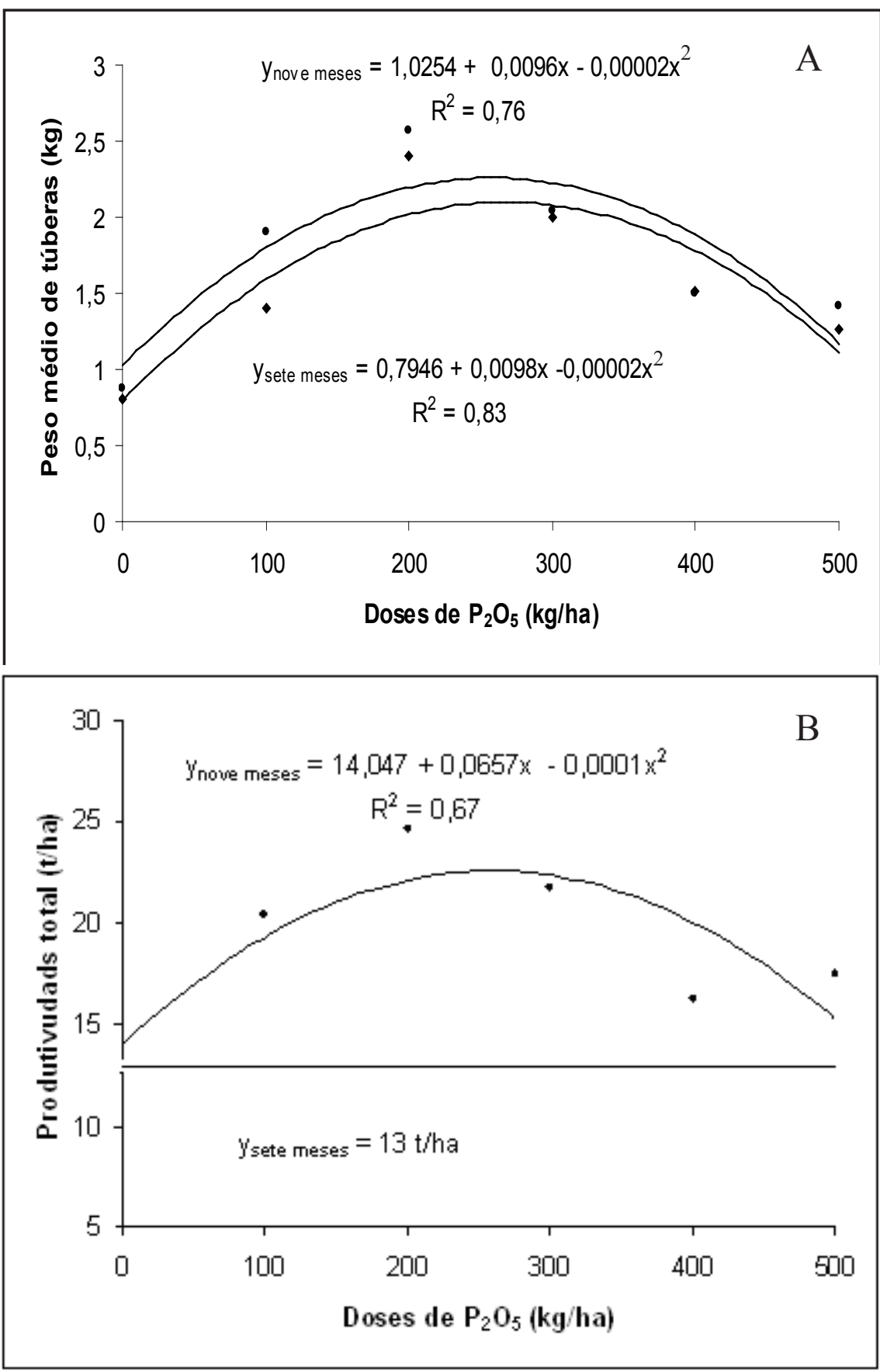

Figura 1. Peso médio e produtividade total de túberas de inhame colhido aos sete e nove meses adubado com doses de fósforo (total yield and average weight of yam tubers harvested in seven and nine months fertilized with rates of phosphorus). Areia, CCA-UFPB, 2009.

total, sendo o valor médio $13 \mathrm{t} \mathrm{ha}^{-1}(\mathrm{Fi}-$ gura 1B). Ao contrário disso, a máxima produtividade comercial de túberas foi $11,8 \mathrm{tha}^{-1}$, alcançada na dose de $266 \mathrm{~kg}$ ha $^{-1}$ de $\mathrm{P}_{2} \mathrm{O}_{5}$ (Figura 2A).

$\mathrm{Na}$ colheita aos nove meses, as doses de 285 e $226 \mathrm{~kg} \mathrm{ha}^{-1}$ de $\mathrm{P}_{2} \mathrm{O}_{5}$ proporcionaram 24,7 e $20,5 \mathrm{tha}^{-1}$ para a máxima produtividade total e comercial de túberas, respectivamente (Figuras 1B e $2 \mathrm{~A}$ ). Isso mostra que a produtividade comercial das plantas colhidas aos nove meses foi $48 \%$ superior em relação aos sete meses.

A produtividade comercial de túberas, independente da época da colheita superou a média nacional citada por Santos (1996) em $10 \mathrm{t} \mathrm{ha}^{-1}$. Esse resultado pode indicar que o fósforo incrementou a produtividade do inhame por atender às necessidades nutricionais do mesmo. O fornecimento de doses adequadas de fósforo, desde o início do desenvolvimento vegetal, estimula o desenvolvimento radicular, é importante para a formação dos primórdios das partes reprodutivas e, em geral, incrementa a produção nas culturas (Corrêa et al., 2004).

$\mathrm{O}$ baixo teor de $\mathrm{P}$ no solo antes do plantio, 10,41 $\mathrm{mg} \mathrm{dm}^{-3}$ (Novais \& Smith, 1999), e a matéria orgânica fornecida juntamente com as doses de $\mathrm{P}_{2} \mathrm{O}_{5}$ em adubação de plantio (15 t ha ${ }^{-1}$ de esterco bovino) auxiliaram na resposta do inhame à aplicação de fósforo. $\mathrm{O}$ baixo teor de fósforo auxiliou na resposta mais acentuada no presente experimento em que houve efeito de doses de $\mathrm{P}$, conforme já verificaram Oliveira et al. (2006). Aliado a isso, a adubação com material orgânico ajudou na formação de um ambiente menos oxidativo com menor interação do $\mathrm{P}$ com os óxidos de $\mathrm{Al}$ e $\mathrm{Fe}$, reduzindo os sítios de fixação e favorecendo o maior aproveitamento do fósforo pela planta (Cubilla et al., 2007).

As máximas porcentagens de túberas classificadas como primeira foram $80 \mathrm{e}$ $90 \%$ nas colheitas aos sete e nove meses após o plantio, obtidas com as doses de 320 e $277 \mathrm{~kg} \mathrm{ha}^{-1}$ de $\mathrm{P}_{2} \mathrm{O}_{5}$, respectivamente (Figura 2B). Esses percentuais representaram, respectivamente, $10,6 \mathrm{e}$ $16,4 \mathrm{t} \mathrm{ha}^{-1}$ de túberas comerciais tipos exportação, indicando que o fósforo melhorou a qualidade do inhame, e a colheita aos nove meses possibilitou maior produção de túberas do tipo exportação. Esse resultado é concordante com o de Raij (1991) e Filgueira (2008) que afirmam que o fósforo em conjunto com o potássio melhora a qualidade das hortaliças.

As doses econômicas foram de 219 e $233 \mathrm{~kg} \mathrm{ha}^{-1}$ de $\mathrm{P}_{2} \mathrm{O}_{5}$ para obtenção de produtividade de 20,19 e $12,88 \mathrm{tha}^{-1} \mathrm{de}$ túberas comerciais aos nove e sete meses, respectivamente. Esses resultados representam incrementos nas colheitas feitas aos nove e sete meses de 19,17 e 3,9 $\mathrm{t} \mathrm{ha}^{-1}$ de túberas comerciais, respectivamente, em relação à ausência do insumo. A dose de máxima eficiência econômica de fósforo foi muito próxima 


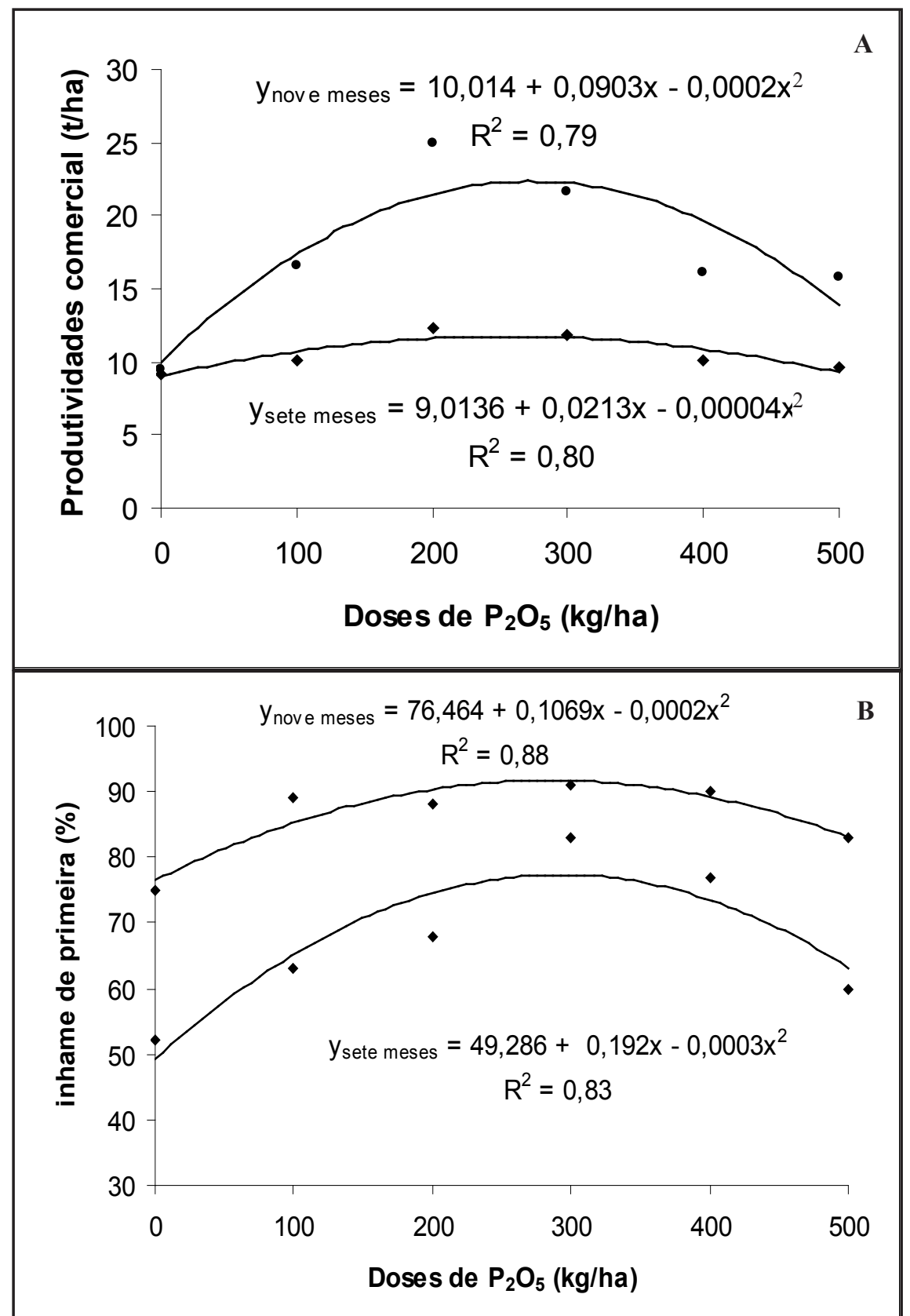

Figura 2. Produtividade comercial de túberas e percentagem de túberas classificado como primeira de inhame, colhido aos sete e nove meses, em função de doses de fósforo (commercial yield of tubers yam and tubers percentage classified as first of yam harvested in seven and nine months in function rates of phosphorus). Areia, CCA-UFPB. 2009.

daquela responsável pela produtividade máxima de túberas comerciais. Sob o ponto de vista do rendimento, a produtividade econômica, superou a produtividade média nacional de túberas.

Considerando-se que o teor de fósforo disponível inicialmente, foi interpretado como baixo, devido à textura arenosa do solo, os resultados obtidos refletem a importância da adubação fosfatada na cultura do inhame, com melhoria no rendimento. Contudo, como foi utilizado um solo com textura arenosa e as doses de $\mathrm{P}_{2} \mathrm{O}_{5}$ foram aplicadas de forma localizada nas covas, futuros estudos deverão ser conduzidos, a fim de avaliar os efeitos de diferentes doses desse nutriente aplicadas de outra forma (a lanço ou em sulco contínuo) e em solo com textura argilosa.

\section{REFERÊNCIAS}

AVALHAES CC; PRADO RM; GONDI ARO; ALVES AU; CORREIA MAR. 2009. Rendimento e crescimento da beterraba em função da adubação com fósforo. Scientia Agrária 10: 75-80.

BARBOSA LJN. 2004. Rendimento do inhame (Dioscorea cayennensis), em função de doses de $\mathrm{N}$ e do manejo da cultura. Areia: CCAUFPB 58p. (Tese mestrado).

CORREAA JC; MAUAD M; ROSOLEM CA. 2004. Fósforo no solo e desenvolvimento de soja influenciada pela adubação fosfatada e cobertura vegetal. Pesquisa Agropecuária Brasileira 39: 1231-1237.

CUBILLA MM; AMADO JTC; WENDLING A; ELTZ FLF; MIELNICZUK J. 2007. Calibração visando à fertilização com fósforo para as principais culturas de grãos sob sistema plantio diretas no Paraguai. Revista Brasileira de Ciência do Solo 31: 1463-1474.

EMBRAPA. Centro Nacional de Pesquisa de Solos. 1997a. Manual de Métodos de Análise de Solo. 212p.

EMBRAPA. Tabuleiros Costeiros. 2007b. Recomendações para o uso de corretivos e fertilizantes no Estado de Sergipe. 251p.

EMBRAPA. Centro Nacional de Pesquisa de Solos. 1999. Sistema brasileiro de classificação de solos. $412 \mathrm{p}$.

FILGUEIRA FAR. 2008. Novo Manual de Olericultura: Agrotecnologia moderna na produção e comercialização de hortaliças. Viçosa: UFV. 422p.

FREITAS NETO PA. 1999. Produtividade e composição mineral do inhame (D. cyennenssis) em função da fertilização organomineral e épocas de colheita. Areia: CCA-UFPB. 72p. (Dissertação mestrado).

LANA RMQ; ZANÃO JUNIOR LA; LUZ JMQ; SILVA JC. 2004. Produção de alface em função do uso de diferentes fontes de fósforo em solos de Cerrado. Horticultura Brasileira 22: 525-528.

MOURA WM; LIMA PC; CASALI VWD; PEREIRA PRG. 2001. Eficiência nutricional para fósforo em linhagens de pimentão. Horticultura Brasileira 19: 306-312.

NATALE W; COUTINHO ELM; BOARETTO A; PEREIRA FM. 1996. Dose mais econômica de adubo nitrogenado para a goiabeira em formação. Horticultura Brasileira 14: 196199.

NOVAIS RF; SMYTH TJ. 1999. Fósforo em solo e planta em condições tropicais. Viçosa, UFV: 399p.

OLIVEIRA AP; FREITAS NETO PA; SANTOS ES. 2001. Produtividade de inhame em função de fertilização orgânica e mineral e de épocas de colheita. Horticultura Brasileira 19: 144-147.

OLIVEIRA AP. 2002. Nutrição e época de colheita do inhame (Dioscorea sp.) e seus reflexos na produção e qualidade de túberas. In: SIMPÓSIO NACIONAL SOBRE AS CULTURAS DO INHAME E DO TARO, 2. Anais... João Pessoa, PB: EMEPA-PB, p.83-981. 
OLIVEIRA AP; SILVA JEL; PEREIRA WE; BARBOSA LJN; OLIVEIRA ANP. 2006. Características produtivas da batata-doce em função de doses de $\mathrm{P}_{2} \mathrm{O}_{5}$, de espaçamentos e de sistemas de plantio. Ciência e Agrotecnologia 30: 611-617.

OLIVEIRAAP; BARBOSA LJN; PEREIRA WE; SILVA JEL; OLIVEIRAANP. 2007. Produção de rizóforos comerciais de inhame em função de doses de nitrogênio. Horticultura Brasileira 25: 79-82.

RAIJ B. V. 1991. Fertilidade do solo e adubação. Piracicaba: Ceres. 343p.
SAEG. 2000. Sistema para análise estatística, versão 8.0. Viçosa-MG: Fundação Artur Bernardes, 2000.

SANTOS ES. 1996. Inhame (Dioscorea spp.): aspectos básicos da cultura. João Pessoa: EMEPA-PB. 158 p.

SANTOS ES. 1998. Sistemas de plantio e tamanhos de túberas-semente de inhame. In: Contribuição tecnológica para a cultura do inhame no estado da Paraíba. João Pessoa: EMEPA-PB, 1998.

SANTOS ES; CASÉ FILHO J; LACERDA JT; CARVALHO RA. 2007. INHAME
(Dioscorea spp.) tecnologia de produção e preservação ambiental. Tecnologia \& Ciência Agropecuária 1: 31-36.

SILVA EC; MIRANDA JRP; ALVARENGA MAR. 2001. Concentração de nutrientes e produção do tomateiro podado e adensado em função do uso de fósforo, de gesso e de fontes de nitrogênio. Horticultura Brasileira 19: 64-69.

SOUTO JS. 1989. Adubação mineral e orgânica do cará da costa (Dioscorea cayennensis Lam.). Areia: CCA-UFPB 57p. (Tese mestrado). 